\title{
A GREEK INSCRIPTION FROM THE DECAPOLIS.
}

\author{
By The Rev. D. Lee Pitcairn, M.A.
}

Towards the end of last year (1911), a rock-hewn tomb was discovered at Beit Rās, which has been identified with the ancient Capitolias. It contained "about a dozen troughs, hewn in the soft rock, with a few bones in them." The objects of glass, etc., of Roman date, were taken possession of by the Turkish officials as soon as they heard of the find. The inscription remains, cut in relief in very clear Greek letters, on the lintel of the tomb.

Miss A. M. Elenson, of the Church Missionary Society, residing at El-Husn, visited the place on December 11, and has sent me the above brief report, with a copy of the inscription:

\section{rAI cI cI cIV \\ $\wedge 1[\overline{C I}[\mathrm{I} \Delta \mathrm{O}$ \\ P믈 $\mathrm{A} \vee \mathrm{TW}$ \\ ERCIH[EN}

\author{
Táïos 'Iov' \\ $\lambda \iota 0$ ' $\mathrm{I} \sigma i \delta \omega$ \\ pos $\dot{\varepsilon} a v t \hat{\omega}$ \\ є̇тoín $\sigma \epsilon \nu$ \\ "Caius Julius Isidorus \\ made it for himself."
}

The shape of some of the letters is peculiar. The $\boldsymbol{\epsilon}, \mathbf{C}, \mathbf{O}$ and $\boldsymbol{W}$ are squared for the convenience of the stone-cutter. It seems curious that the letter $\boldsymbol{\omega}$, Omega, should occur in two different forms, in two consecutive lines, at the end of the second and at the end of the third. 